\title{
Proportioning systems in Wirt C. Rowland's Union Trust Guardian Building
}

\author{
Michael G. Smith • Rachel Fletcher
}

Published online: 2 December 2014

(C) Kim Williams Books, Turin 2014

\begin{abstract}
American architect Wirt C. Rowland designed and constructed Detroit, Michigan's Union Trust Guardian Building in the late 1920s, during his tenure with Smith, Hinchman and Grylls Associates. It is a masterpiece of American commercial architecture and one of the foremost Art Deco structures in the world. The bold geometric patterns that adorn the Guardian's surfaces announce that geometry is in play. We propose that Rowland organized the building's complex colorful designs around geometric proportioning systems. We review geometric methods available to Rowland in his day, and then reconstruct portions of the Guardian's design utilizing dynamic symmetry, ad quadratum, and ad triangulum constructions.
\end{abstract}

Keywords Descriptive geometry - Geometric construction · Proportional systems · Wirt C. Rowland · Union Trust Guardian Building · Detroit . Michigan · Modern American commercial architecture · Dynamic symmetry · Root-two $\cdot$ Ad quadratum $\cdot$ Ad triangulum $\cdot$ Incommensurate values · Art Deco

I see in much of the work of the past certain of the same principles so loudly vaunted as new. (Rowland 1940: p. 4).

\section{G. Smith}

4874 School Bell Ln., Bloomfield Hills, MI 48301-1350, USA

e-mail:mgsmith.usa@gmail.com

R. Fletcher $(\bowtie)$

113 Division St., Great Barrington, MA 01230, USA

e-mail: rfletch@bcn.net 


\section{Introduction}

The forty-story Union Trust Guardian Building in Detroit, Michigan, constructed from 1927 to 1929, is a masterpiece of American commercial architecture and one of the foremost Art Deco structures in the world. American architect Wirt C. Rowland (1878-1946) designed the building at the height of the city's financial prominence. It was, on completion, the city's second tallest building and is today the fifth tallest. We explore the possibility that Rowland organized the Guardian's bold and colorful designs around geometric proportions, and we consider potential influences and sources for techniques he employed. These include geometricallybased theories of proportion proposed in the nineteenth and early twentieth centuries to explain the architecture of antiquity through the Middle Ages, and "dynamic symmetry", the system that Jay Hambidge (1867-1924) advanced in the early twentieth century for explaining ancient Egyptian and Greek structures.

In many ways I have felt that, if a man should know those principles and could work freely among them his work would be fresh and still be human ... (Rowland 1940: p. 4).

\section{Architect Wirt C. Rowland}

Wirt C. Rowland was born December 1, 1878, in the village of Clinton, Michigan, about 50 miles west of Detroit, and from an early age was an avid reader, talented artist, and self-taught musician. Academically, Rowland excelled at solid geometry and, later in life, recognized its influence on the Guardian: "I didn't like mathematics, but solid geometry-I had them there, and passed perfect on my final exam in that subject. (Look at the Union Guardian Building!)" (Rowland 1939: p. 1.) From 1901 to 1910, Rowland worked for renowned Detroit architect George D. Mason, under whose guidance, and with access to Mason's vast library of architectural books and journals, Rowland's knowledge and skills grew rapidly. In 1905, he was responsible for the design of Detroit's largest hotel. He worked next for Albert Kahn and eventually became Kahn's chief designer for projects such as the General Motors Building. Rowland joined Smith, Hinchman and Grylls in 1922. By 1930, he had designed four monumental buildings-the Buhl, Greater Penobscot, Union Trust Guardian, and First National Bank-that largely defined Detroit's commercial architectural style and dominated its skyline. Rowland designed the Guardian Building during his 8 year tenure as head designer for Detroit's largest architecture and engineering firm of Smith, Hinchman and Grylls Associates. ${ }^{1}$

\footnotetext{
1 The Guardian Building is located at 500 Griswold Street, Detroit, Michigan 48226, and is listed on the National Register of Historic Places. The main and banking lobbies are open to the public; free tours are available through Pure Detroit.
} 


\section{The Guardian Building}

The Union Trust Guardian rises 632 feet from the southeast corner of Griswold Street and Congress Street, a location that places it at the epicenter of Detroit's financial district (Fig. 1). It was commissioned to provide new headquarters for the rapidly growing Union Trust Company. During construction, Union Trust merged with one of its rivals, the Guardian Trust Company, and became the Union Guardian Trust Company. Following the stock market crash of 1929 and the subsequent Depression, Detroit's engine of affluence stalled. In 1933, Union Guardian failed, like many U.S. banks teetering on the edge of insolvency. The Union Trust Building changed its name to the Guardian Building, managed by a tenant group.

Fig. 1 Wirt C. Rowland. Union Trust Guardian Building. Griswold Street and Congress Street. Photo: Michael G. Smith

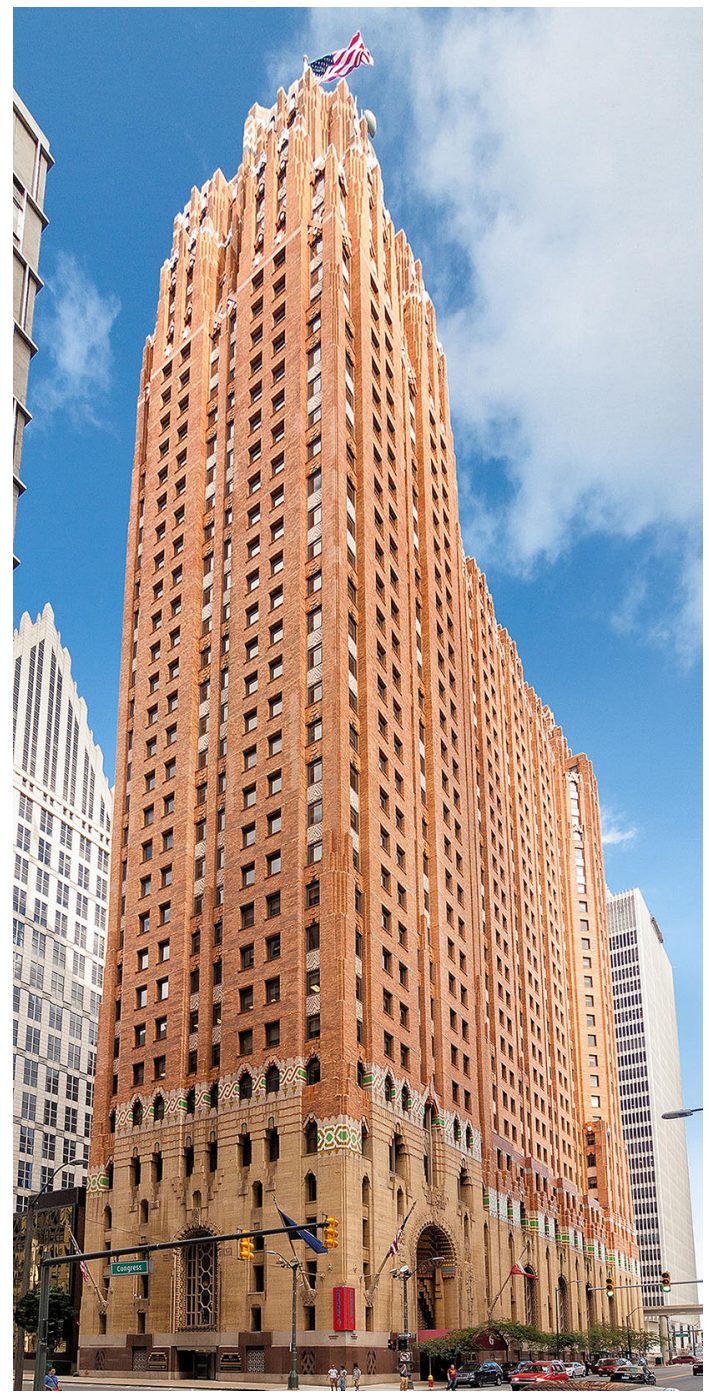


The building has at times been called the "Cathedral of Finance". Reporters applied the moniker when it opened. The name "Temple of Banking" had already been taken for Rowland's nearby First National Bank Building. Rowland recognized the Guardian's elongated exterior, with its tall tower in front and smaller one at the rear, resembled "almost the form of a huge cathedral, with the high tower at the north end, the nave, with its clerestory and aisles stretching toward the south and terminated by the apse, or small octagonal tower" (Rowland 1929: p. 3).

The building's entry portal is located at the north end of the Griswold Street side. To add depth and drama to the entrance, Rowland set the portal inside the building line and beneath a half-dome containing large windows and colored tile designs, with carved stone figures on either side. The main lobby lies just inside the entrance; the much larger banking lobby lies to the right, up a half flight of stairs. Both areas open to a height of four stories (Fig. 2).

Straight ahead, as one enters the building, a large mural of colored tile dominates the east wall of the main lobby. Two elevator alcoves flank the mural, with spectacular stepped ceilings of colored terra cotta tile. The alcoves culminate in windows of colored glass; each one depicts a winged, human figure holding aloft an eight-sided form. Together, the alcoves and mural create a single dramatic composition in symmetrical arrangement (Fig. 3).

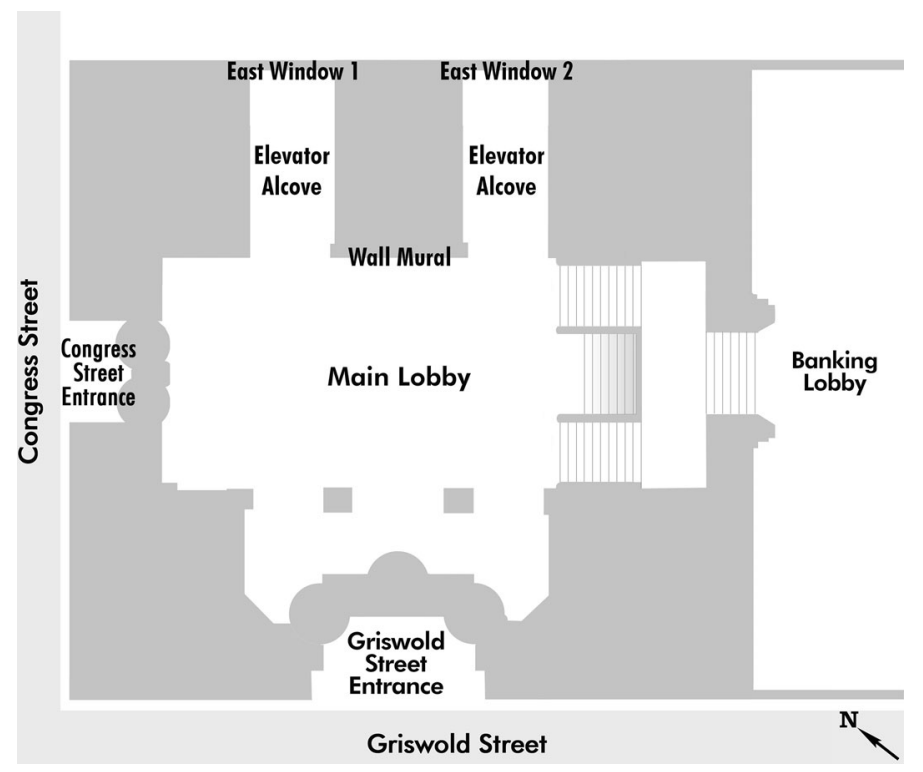

Fig. 2 Wirt C. Rowland. Union Trust Guardian Building. Floor plan of the main entrance lobby. Image: Smith, Hinchman and Grylls Associates, original drawings for the Union Trust Building. Redrawn by Michael G. Smith 


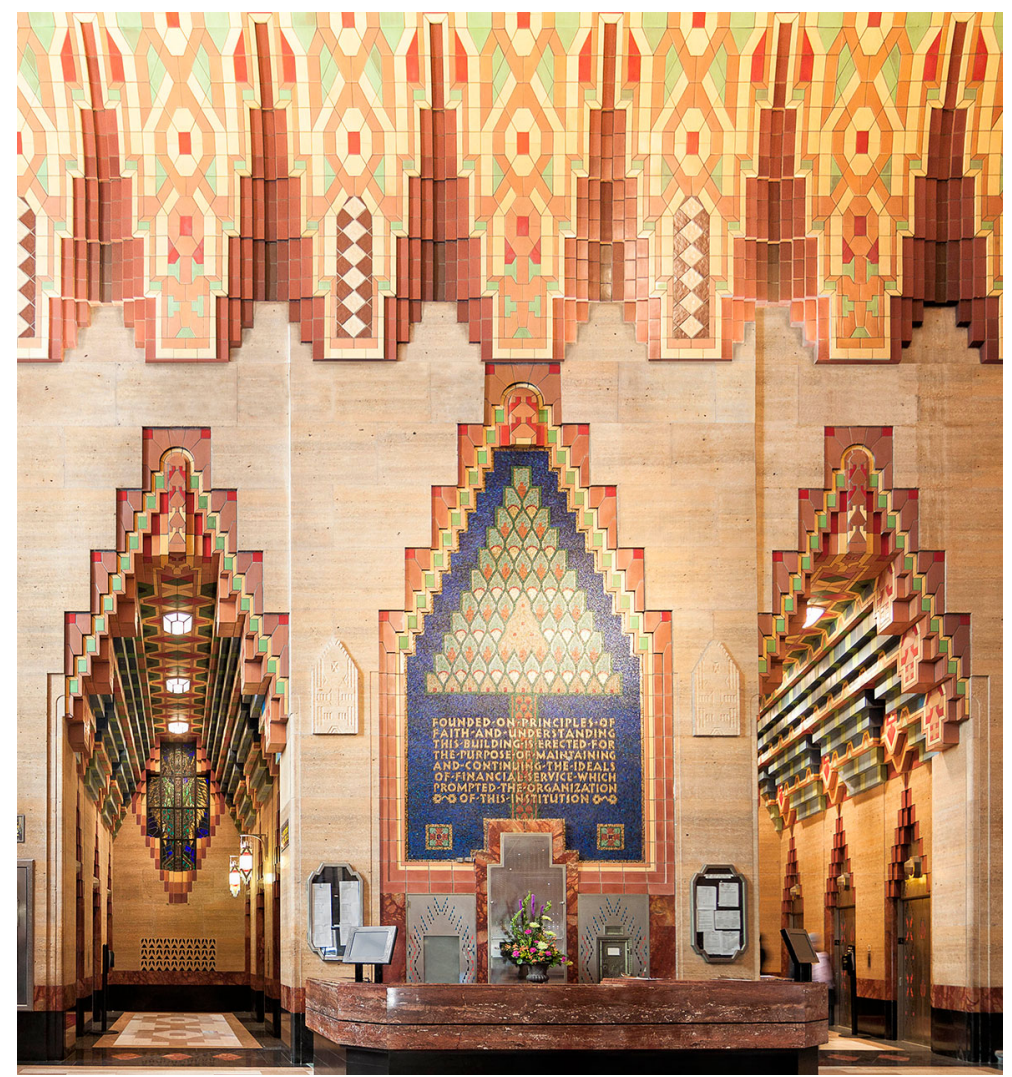

Fig. 3 Wirt C. Rowland. Union Trust Guardian Building. Main lobby east wall. Photo: Michael G. Smith

\section{Artistic features}

Rowland developed a modern American design for the Guardian Building, with features inspired by the Native American city-dwelling Indians of the Southwest. Two massive stone-carved Indian figures flank the building's entrance. The ceiling of the banking lobby is a suspended mat of canvas painted in designs reminiscent of Indian blankets. The bright reddish-orange brick used on most of the building's exterior recalls the red rock formations of Canyon de Chelly in northeast Arizona. ${ }^{2}$

Except for the large, round-arched windows within the building's six-story base section, Rowland's design relies on stepped and angled arches. ${ }^{3}$ Stepped shapes

\footnotetext{
${ }^{2}$ Compare Rowland's designs with (Cushing 1886: pp. 488, 518; Nordenskiöld 1893: pp. 87-92; Peet 1899: p. 264). By 1925, the Detroit Public Library carried G. Nordenskiöld's The Cliff Dwellers of Mesa Verde (1893) and Stephen Denison Peet's The Cliff Dwellers and Pueblos (1899) (Detroit Public Library 1925: p. 70).

${ }^{3}$ Rowland did not look to Mesoamerican or similar sources to design the arches. In 1929, he wrote: "The stepped arches used in this portion of the façade are merely the stepped forms reversed and seemed appropriate to the character of the upper forms. They were not derived from any style or from Mayan architecture as often suggested" (Rowland 1929: p. 3).
} 
build on the right angles of piled bricks, which comprise most of the building's surface. Angled arches of terra cotta and other non-brick materials form $60^{\circ}$ angles. Angles of $60^{\circ}$ and $45^{\circ}$ appear in many permutations on the outside of the building and throughout the interior. The massive crown atop the building's north tower, as well as doorknobs and backs of office chairs, incorporate $60^{\circ}$ angles. Angles measuring $45^{\circ}$ dominate the composition of the main lobby's east wall, including stepped arches fronting the elevator alcoves, as well as window muntins at the rear of the alcoves.

The building's most important design element is color, which Rowland introduced by composing colored materials in orderly arrangement. He realized that striking geometric patterns of colored shapes could substitute for decorative columns, cornices, and mouldings. In 1932, he wrote: "Our attention has often been on ornament. This has partially caused the colorless character of our building. Is [sic] seems to me that color is an answer to a lack of ornament..." (Rowland 1932: p. 6).

Executing the Guardian's design entailed an unprecedented marriage of mass production with quality materials and craftsmanship. Rowland worked closely with Mary Chase Perry of Detroit's Pewabic Pottery to develop tile colors that could be distinguished when viewed from a distance and would be consistent in size, shape, and color when produced in large quantities. The volume of tiles required was well beyond Pewabic's capabilities; larger firms produced them according to Perry's specifications.

The Guardian employed low-cost brick cladding for most of its exterior; high quality materials were used elsewhere. Rowland selected an unusual blood red marble for the main lobby, which he secured from a quarry in Africa that had been closed for three decades. He paneled several offices on the first 16 floors in rare woods from around the world, with insets designed in the stepped angle motif.

For hardware such as doorknobs, stair rails, teller cages, and mail chutes, Rowland selected Monel metal with either a matte or polished finish. Monel, a kind of alloy composed of nickel and copper similar in appearance to stainless steel, was a radical departure from brass, which was the standard of the time. A massive screen of Monel metal separates the main lobby from the banking lobby. While Monel metal required little maintenance, it proved difficult to work. Handcrafting the material was out of the question, so machines incised the designs. Translucent pieces of Tiffany glass were hand-fitted into machine-incised patterns on the Monel elevator doors.

In style, the Guardian Building falls squarely within Art Deco. Rowland and his peers preferred the term Modernism to describe their break with historical modes, even as some applied classical principles to modern construction methods. The Arts and Crafts Movement, with its emphasis on quality materials and craftsmanship, has also been cited as an influence on the Guardian and can be seen in the architect's earlier designs. But by 1926, he operated in uncharted territory and developed new design methods. The building was so different, in fact, that it stirred considerable 
controversy. The Christian Science Monitor described it as "astonishing" and "ultra modern" (D. D. K. 1929: p. 8). The Wall Street Journal said the structure "is conspicuous for its modern design, employing lavish use of color" (WSJ 1929: p. 4). The Detroit Free Press stated, "It comes close to being revolutionary, a definite break with decorative tradition" (Richards 1929: p. 1).

\section{Methods of proportion and composition}

Did Rowland devise a geometric proportioning system to compose the Guardian's bold and colorful design? Did he borrow from other sources? The lattice-like tile patterns that adorn the Guardian's surfaces recall the geometric networks of angular lines proposed in the nineteenth and early twentieth centuries as explanations of architectural designs of antiquity through the Middle Ages (Bork 2011: pp. 10-13) (Fig. 4). Another candidate is dynamic symmetry, the geometric technique that Jay Hambidge proposed in modern times to explain ancient Egyptian and Greek structures.

Fig. 4 Eugène Emmanuel Viollet-le-Duc. Equilateral and isosceles "Egyptian" (base to height in ratio 4:2.5) triangles applied to a cross-section of the Cathedral Notre Dame in Amiens (Viollet-le-Duc 1875: p. 427)

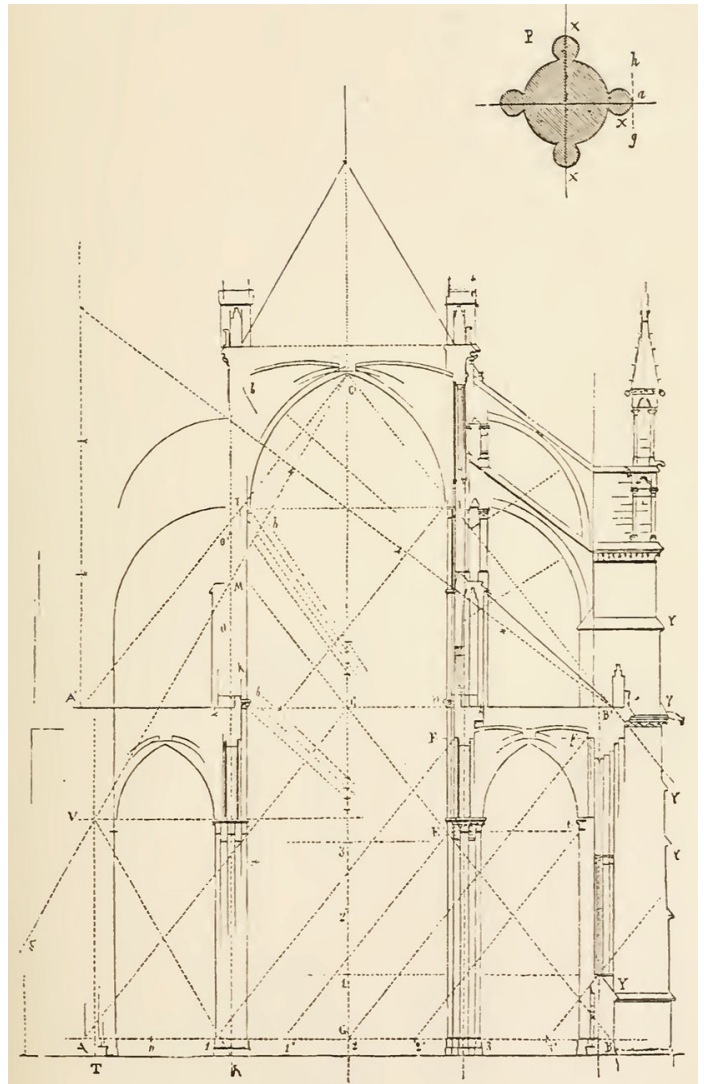


Fig. 5 Eugène Emmanuel Viollet-le-Duc. Equilateral triangles applied to the façade of a basilica (Viollet-le-Duc 1875: p. 415)

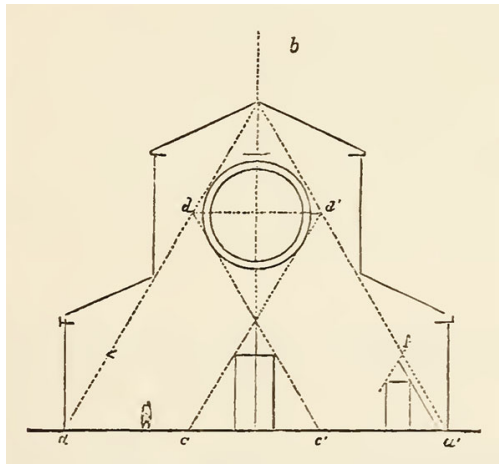

Rowland studied Classical and Medieval architectural design on his own and in 1909-1910, a year he spent at Harvard's Graduate School of Design, Department of Architecture, where he had gone in order to gain "a better foundation in architectural history". ${ }^{4}$ He would have learned about architectural theorists such as Eugène Viollet-le-Duc (1814-1879), whom George Harold Edgell, dean of Rowland's school at Harvard, lauded as a "profound medievalist" (Kimball and Edgell 1918: p. 327). By 1925, the Detroit Public Library carried Viollet-le-Duc's Discourses on Architecture. ${ }^{5}$ It contains drawn lattices of intersecting triangles that locate and align the elements of a building's façade (Viollet-le-Duc 1875: pp. 414-27). For example, he applies the equilateral triangle, which "of all the rest, most satisfies the eye", to the façade of a basilica (Viollet-le-Duc 1875: p. 414) (Fig. 5). Viollet-le-Duc's diagram resembles the complex $60^{\circ}$ angular pattern that decorates the tiled ceiling of the Guardian's main lobby (Fig. 6).

In contrast to theorists who offered arithmetic interpretations based on whole number modules, Viollet-le-Duc and others proposed that architects of antiquity through the Middle Ages employed geometric techniques to achieve proportion. He describes a "generative", "harmonic system" with geometry as "the natural point of departure", in which the triangle, "the most perfect of geometrical figures", maintains a specific proportion between widths and heights. The result is that "every detail should bear a defined relation to the general composition...". "Among Greek and medieval artists alike this principle was recognized and practiced;... everything was relative, and every member occupied a necessary and proportionate part of the general harmony..." (Viollet-le-Duc 1875: pp. 411, 431, 434).

The surviving portfolio of thirteenth-century artist Villard de Honnecourt (2006) provides early evidence that ad triangulum and ad quadratum geometries were known in medieval times. In the nineteenth century, complex networks of angular lines to locate and align key features, based on ad triangulum, ad quadratum, and, to

\footnotetext{
4 (Rowland 1910a) Rowland registered for "Technical and Historical Development of the Ancient Styles, with especial reference to Classic Architecture" and "Technical and Historical Development of the Medieval Styles of Architecture" (Briggs 1912: p. 57; Rowland 1910b).

5 In addition, the library carried Jay Hambidge's Parthenon and other Greek Temples; Their Dynamic Symmetry (1924), F.M. Lund's Ad Quadratum (1921), and E. E. Viollet-le-Duc's La cité de Carcassonne (1881) and Habitations moderns (1877) (Detroit Public Library 1925: pp. 9, 35, 67).
} 

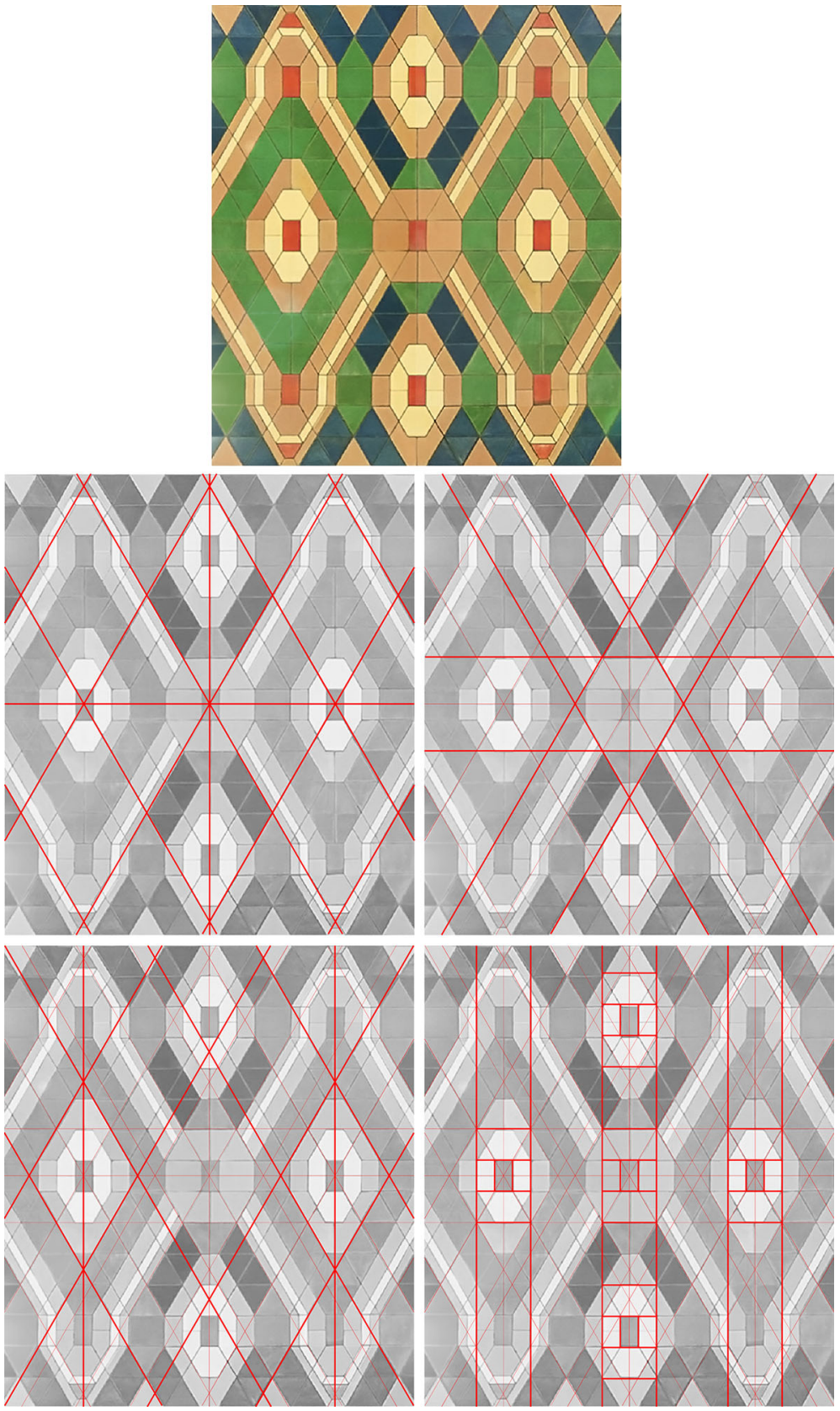

Fig. 6 Wirt C. Rowland. Union Trust Guardian Building, section of main lobby tiled ceiling, with $60^{\circ}$ angular overlays. Photo and overlay by Michael G. Smith, redrawn by Rachel Fletcher 

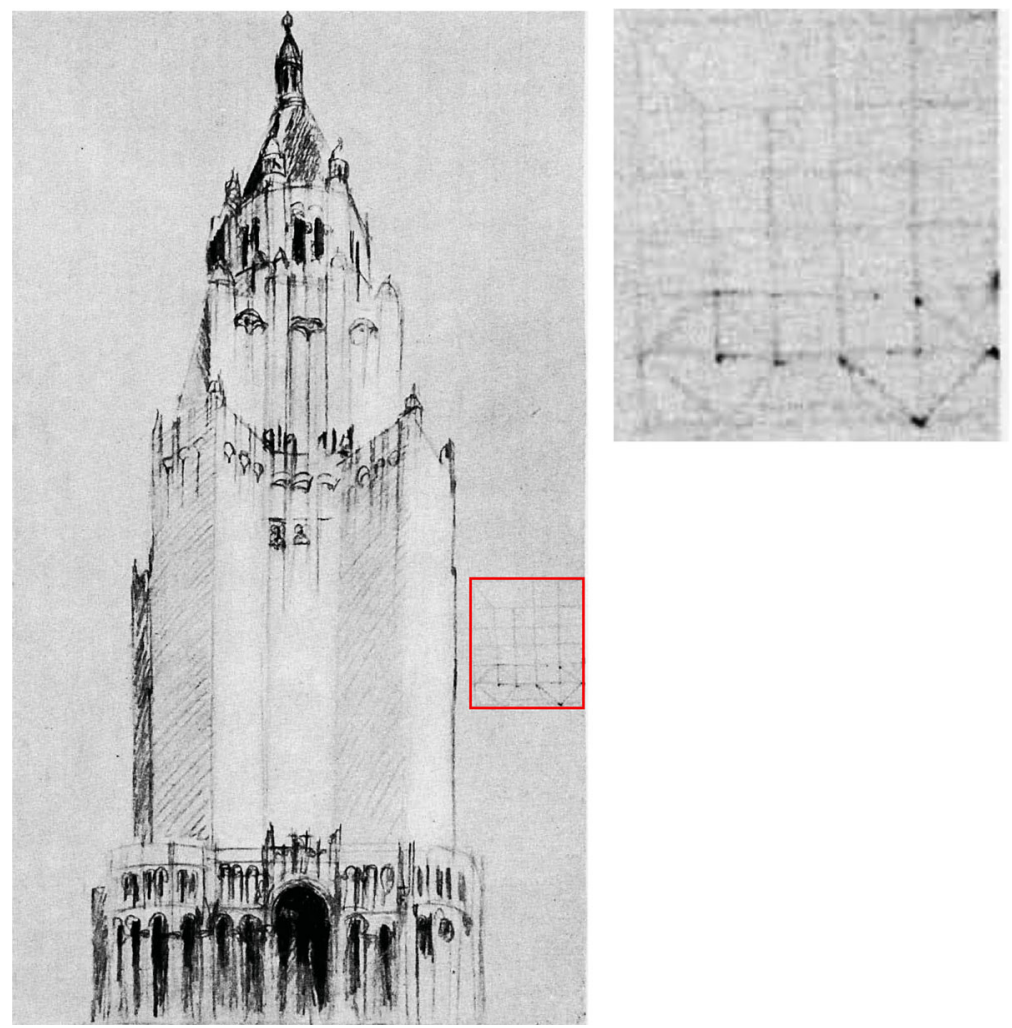

Fig. 7 Wirt C. Rowland. Suggestive sketch study for an office building (1925), with detail enlarged (Breiby 1925: p. 72)

a lesser extent, $\sqrt{ } 5$ and golden section constructions, were common, if speculative, interpretations of ancient and medieval structures. ${ }^{6}$

Rowland's preference for $60^{\circ}$ and $45^{\circ}$ angles is consistent with ad triangulum schemes based on the $60^{\circ}$ equilateral triangle and ad quadratum systems that develop from the side and diagonal of a square, or the sides and hypotenuse of a $45^{\circ}$ isosceles right triangle. His free-hand sketch from 1925 indicates that he experimented with these techniques. The sketch accompanies a study for an unnamed office building and depicts a lattice composed in ad quadratum fashion (Fig. 7).

\footnotetext{
${ }^{6}$ Viollet-le-Duc and other geometry-based theorists such as Frederik Macody Lund observed proportional systems in different ways and suggested a variety of solutions. Sometimes they proposed contradictory schemes for the same elevation or plan. Robert Bork notes that Violette-le-Duc and Lund presented conflicting hypothetical overlays for the identical cross-section of Cathedral Notre Dame in Paris. Bork adds that both theorists based their interpretations on a conjectural reconstruction of Notre Dame by Viollet-le-Duc, which subsequent scholarship rejected. In modern times, more rigorous geometric studies of medieval architecture have yielded promising analyses supported by archaeological and documentary evidence (Bork 2011: pp. 11-12).
} 
With these methods, Rowland could unify complex spatial compositions and rapidly design in volume large structures that were well-proportioned and aesthetically pleasing. Another potential source for the Guardian's inherent geometric proportions is Jay Hambidge's theory of dynamic symmetry. In Hambidge's system of diagonals and reciprocals, incommensurable ratios, rather than those based on whole numbers, unite multiple spatial levels.

An avid reader of architectural publications, Rowland could have learned about dynamic symmetry when Hambidge's "Symmetry and Proportion in Greek Art" appeared in the November 12, 1919, issue of The American Architect, prompting extensive and lively discourse (Hambidge 1919: pp. 597-605). He may have read Hambidge's "Dynamic Symmetry and Modern Architecture" in the November, 1921, issue of Architecture (Hambidge 1921a: pp. 343-45). ${ }^{7}$ At any rate, Detroit's architectural and industrial arts circles discussed Hambidge's theory. During the 1920s, the city's public schools taught dynamic symmetry in elementary schools and colleges; the University of Michigan and other state schools added it to numerous art, architecture, and decorative design studies. ${ }^{8}$

In 1932, not long after completing the Guardian Building, Rowland engaged in public debate with fellow architects about the future of architectural design. ${ }^{9}$ Some favored the continued imitation of established historical designs; others chose to free themselves of the past by abandoning well-established design principles. Rowland sought to apply the best design principles of the past to present challenges (Rowland 1932).

Rowland lauded the Greek temple of the Periclean era as "the most important attainment in building which the world has ever seen", whose logic "left indelible marks" on the highest architectural achievement through the Gothic period (Rowland 1932: pp. 1, 4). He attributed this to a "fine balance of the imagination disciplined by the intellect" and an "ethical attitude toward every creative effort". Rowland believed that success in all forms of art rested on "the beauty of proportion, articulation, and structure which the Greeks found in the human body" and on "their control of placing and proportion by using the laws of mathematics which they discovered" (Rowland 1931: pp 15). One wonders if he was mindful of dynamic symmetry and Hambidge's preference for incommensurable proportions when he wrote: "The Greeks were masters also of geometric principles which have since not been practiced. These subtilties [sic] of measurement were a medium which helped them to finally attain that mastery of expression. By these subtilties they made a great science of building which was not obtained by the repetition of a fixed unit of scale" (Rowland 1932: p 4).

\footnotetext{
7 Or Hambidge's "Dynamic Symmetry: The Rediscovery of the Basic Principles of Greek Art" in the July 1921 issue of Scientific American Monthly (Hambidge 1921b: pp. 23-28).

8 (Architectural Yearbook 1927: p. 50; Board of Education 1925: p. 405; Detroit News 1930: p. 1; Rollins 1921: p. 68; Special Art Course 1921: p. 14; University of Michigan 1926: pp. 76, 79, 260; University of Michigan 1927: p. 508).

9 The Michigan Society of Architects held the debate "Symposium on Modernism" on May 25, 1932, with participants Wirt Rowland, Arthur K. Hyde, and Herbert G. Wenzell. The society's Weekly Bulletin published Hyde's comments on June 7, 1932, and followed with comments by Rowland and Wenzell on June 14 and June 21, respectively.
} 


\section{Dynamic symmetry}

Dynamic symmetry relies on incommensurable ratios that cannot be expressed in whole numbers, but that inhabit elementary geometric shapes precisely. Unlike ratios composed of whole numbers, incommensurable ratios repeat endlessly through spatial divisions. Hambidge traced the origins of dynamic symmetry to ancient Egypt and sixth- or seventh-century BCE Greece. Subsequently, it developed in Euclidean geometry and for 300 years produced some of the finest art of the Classical period (Hambidge 1920: pp 7-8). To Hambidge, dynamic symmetry expressed "the relationship which the composing elements of form in design, or in any organism of nature, bear to the whole. In design, it is the thing which governs the just balance of variety in unity" (Hambidge 1967: p. xii).

The $60^{\circ}$ and $45^{\circ}$ lattices apparent in the Guardian's geometric designs recall the triangulated lines of medieval proportioning as they develop from ad triangulum and ad quadratum figures. They also express the incommensurable ratios at the core of Hambidge's system. The half-side and altitude of any $60^{\circ}$ equilateral triangle (60-60-60) are in ratio $1: 1.7320 \ldots$ or $1: \sqrt{ } 3$ (Fig. 8, left). The side and hypotenuse of any $45^{\circ}$ isosceles right triangle (45-45-90) are in ratio $1: 1.4142 \ldots$ or $1: \sqrt{ } 2$ (or, put another way, the side and diagonal of any square are in ratio $1: \sqrt{ } 2$ ) (Fig. 8 , center). The sides of any $45^{\circ}$ isosceles triangle (67.5-67.5-45) join two diagonals of an octagram, or two rotated squares (Fig. 8, right).

In dynamic symmetry, incommensurable ratios repeat through endless spatial divisions and express the relationship between one level and the next. A $\sqrt{ } 2$ rectangle proportioned to the side and diagonal of a square divides indefinitely into two proportionally smaller reciprocal rectangles in ratio $1: \sqrt{ } 2$. The long side of each reciprocal is equal in length to the short side of the original (Fig. 9, left). As each new reciprocal divides in similar fashion, the side lengths of successive rectangles form a perfect geometric progression $(1, \sqrt{ } 2,2,2 \sqrt{ } 2 \ldots)$. The diagonals of the original rectangle and its reciprocal intersect at right angles, where they divide into radii vectors that progress continually in $\sqrt{ } 2$ proportion (Fig. 9 , right). In similar fashion, a $\sqrt{ } 3$ rectangle proportioned to the half-side and altitude of an equilateral triangle divides indefinitely into three proportionally smaller reciprocal rectangles in ratio $1: \sqrt{ } 3$ (see Fig. 6 , lower right).
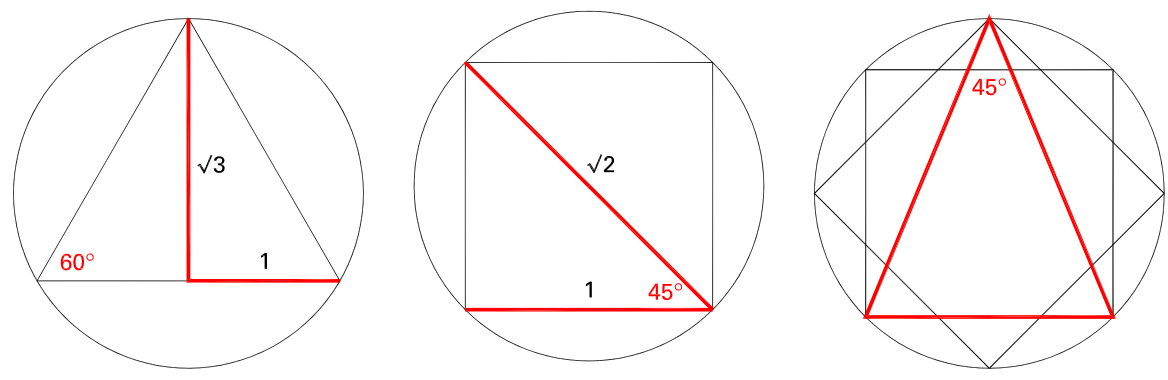

Fig. 8 Ratios in $45^{\circ}$ and $60^{\circ}$ triangles. Image: Rachel Fletcher 

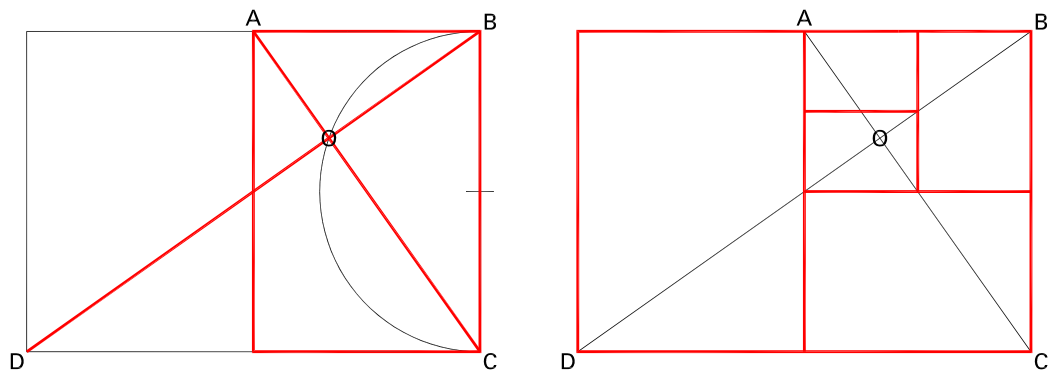

$A B: B C:: B C: C D:: 1: \sqrt{ } 2$

$A C: B D:: 1: \sqrt{2}$

$\mathrm{OA}: \mathrm{OB}:: \mathrm{OB}: \mathrm{OC}:: \mathrm{OC}: \mathrm{OD}:: 1: \sqrt{ } 2$

Fig. 9 Rectangle based on $\sqrt{ } 2$. Image: Rachel Fletcher

\section{Main lobby east wall}

The $\sqrt{ } 2$ ratio plays out dynamically along the east wall of the Guardian's main lobby, which features a central mural of colored tile and glass, with elevator alcoves on either side. Stepped arches of $45^{\circ}$ frame the mural and alcoves in front, extend overhead through the alcoves, and conclude at the rear wall, where they frame rhomboidal-shaped windows (shaded area, Fig. 10.1). The $\sqrt{ } 2$ proportion persists through multiple spatial levels, from the relative locations of the elevator alcoves and mural to the placement of individual muntins.

Primary and secondary elements within Rowland's measured elevation conform to a simple octagonal figure composed of two rotated squares in active (point up) and passive (base down) positions. ${ }^{10}$ Two sets of overlapping diagonals locate the large rhomboid shape within each alcove window. From here, the construction yields secondary lines that locate various details within the window and tile frame design. The same geometric figure informs the composition of the wall as a whole and situates the alcoves and central mural in relation to one another.

To create this geometry, locate the rhomboidal window and its tile frame, on the right.

- Draw vertical and horizontal axes through the center.

- From the center, draw a circle of radius as shown.

- Inscribe a regular octagon. Draw four diagonals as shown.

The diagonals converge at $45^{\circ}$, above and below; they locate the window's outer diagonal muntins.

\footnotetext{
${ }^{10}$ The geometric analyses we propose for the Guardian's main lobby east wall (Fig. 10) and Congress Street spiral decoration (Fig. 12) are based on measured drawings of Rowland's designs prepared by Smith, Hinchman and Grylls Architects and Engineers. If Rowland developed his designs geometrically with compass and straight-edge rule, their precise measures would be rounded to feet and inches composed of whole numbers. This would not influence one's experience of the building, but could affect how precisely the geometric overlays align with measured plans.
} 


\section{1}

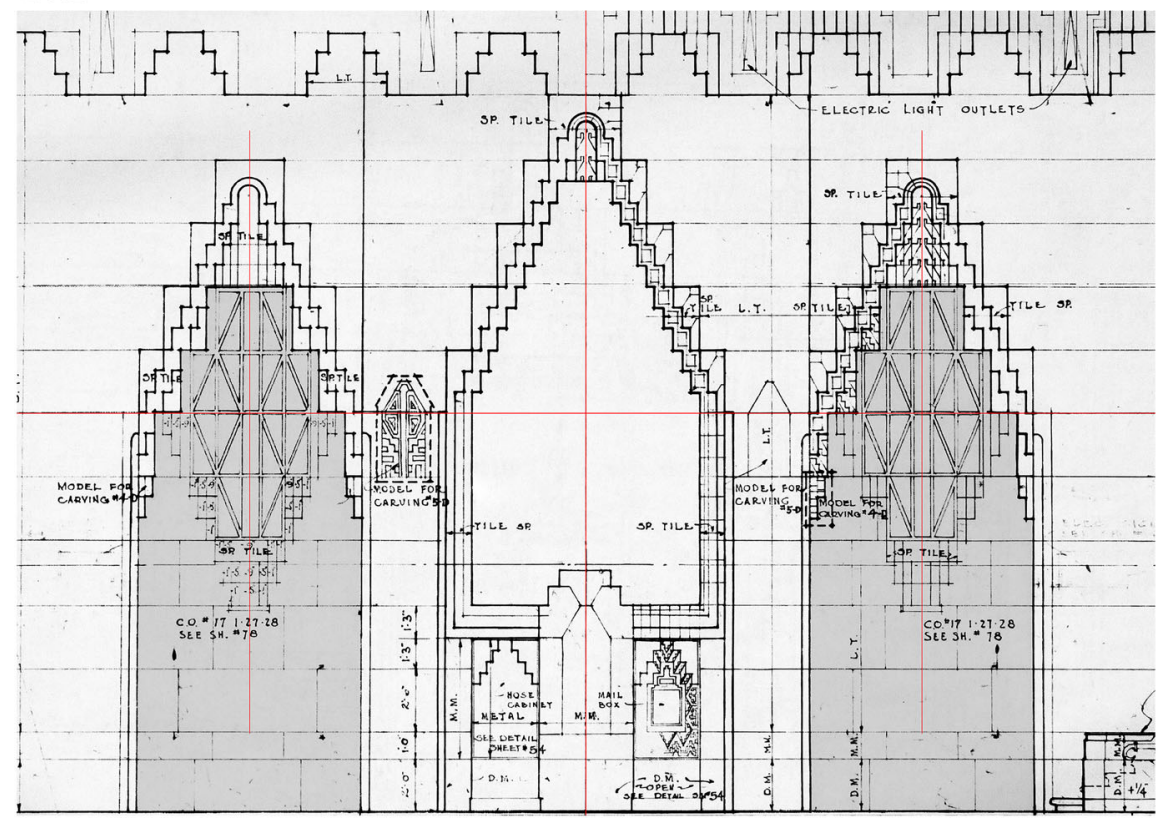

Fig. 10.1-10.7 Wirt C. Rowland. Union Trust Guardian Building. Main lobby east wall, measured elevation, with overlay. Image: Smith, Hinchman and Grylls Associates, original drawings for the Union Trust Building, job number 5776, sheet number 56 "Details of Foyer Entrances, Lobbies, etc." August 15, 1927. Overlays by Rachel Fletcher

The side and diagonal of the octagon are in ratio $1: 1+\sqrt{ } 2$.

The diagonals divide the diameter of the circumscribing circle in ratio $1: \sqrt{ } 2: 1$ (Fig. 10.2).

- Inscribe two squares in active and passive position, as shown (Fig. 10.3).

The squares and diagonals locate window muntins and related tile elements (Fig. 10.4).

The squares and diagonals delineate the window's geometric design (Fig. 10.5). Isosceles triangles measuring $45^{\circ}$ govern the stepped tile arches and window frames; they recall the networks of angular lines proposed in the nineteenth century for architecture of the Middle Ages (Fig. 10.6).

Forty-five degree isosceles triangles and their inherent $\sqrt{ } 2$ proportions unify the overall composition of the lobby wall (Fig. 10.7).

There is no documentary evidence that Rowland composed the east wall in this fashion, or that he applied another geometric technique with intent. But the analysis demonstrates that $\sqrt{ } 2$ proportions persist through several layers of composition and unify its primary and secondary elements. 

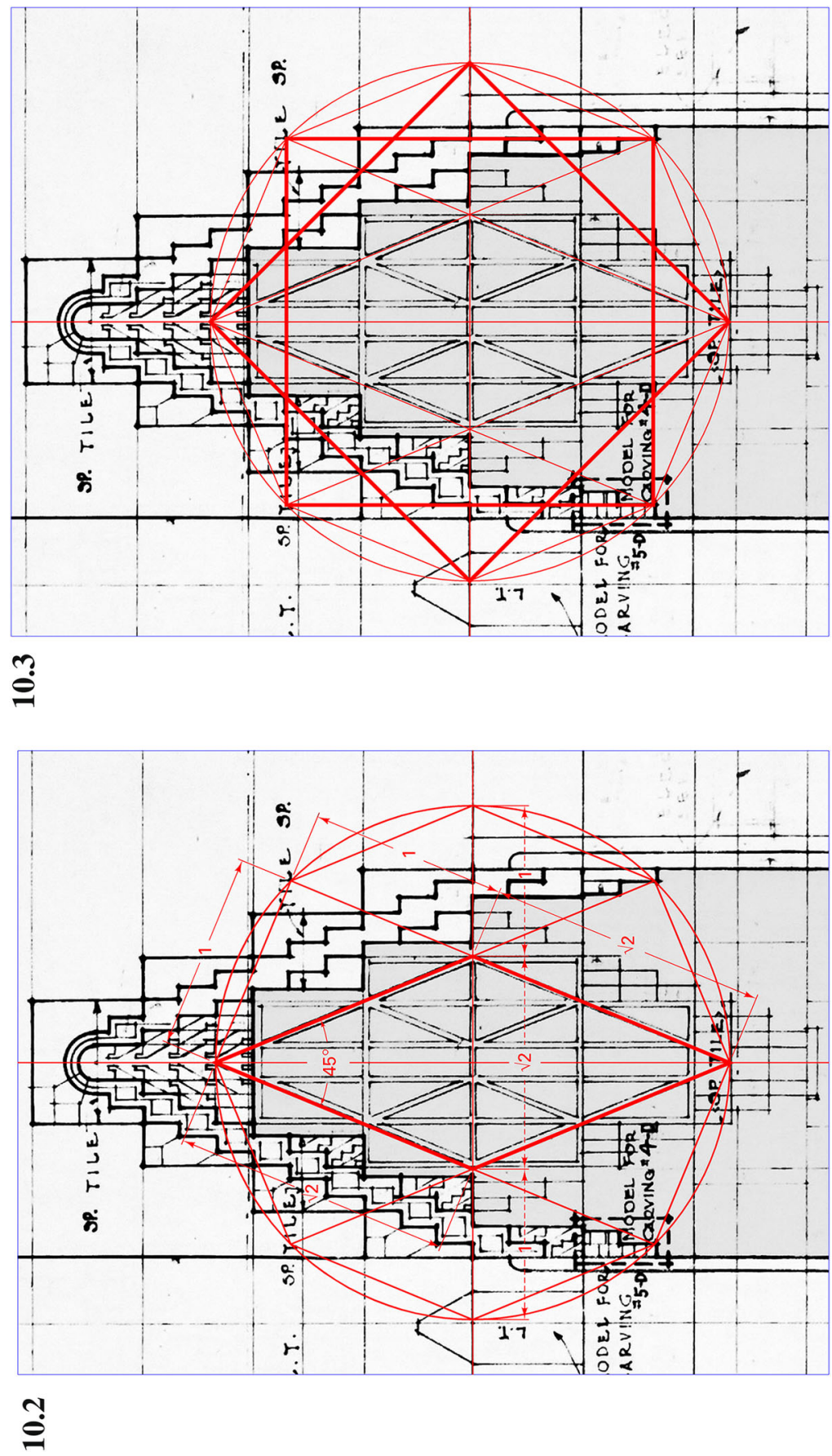

Fig. 10.1-10.7 continued 

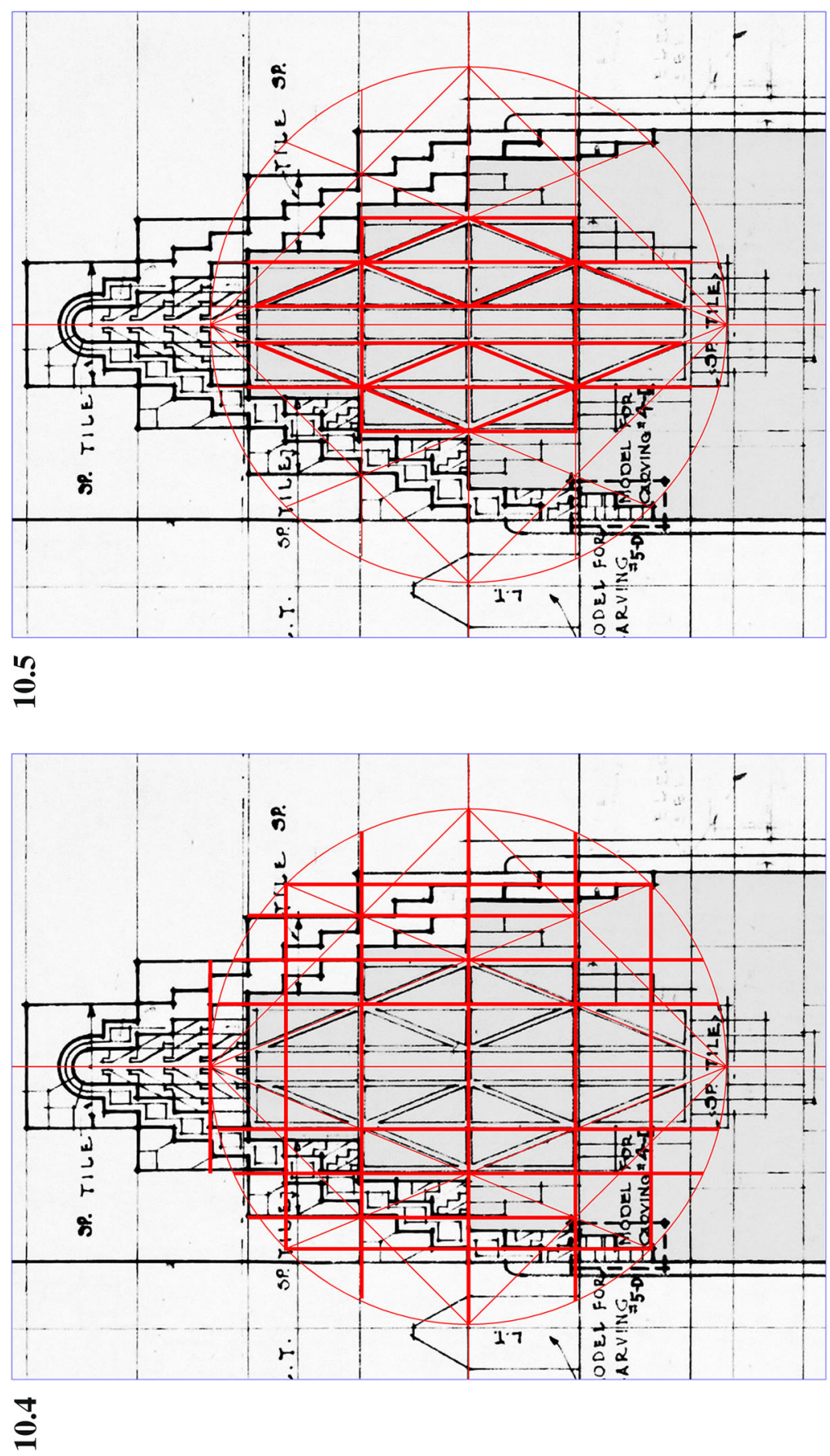

Fig. 10.1-10.7 continued 


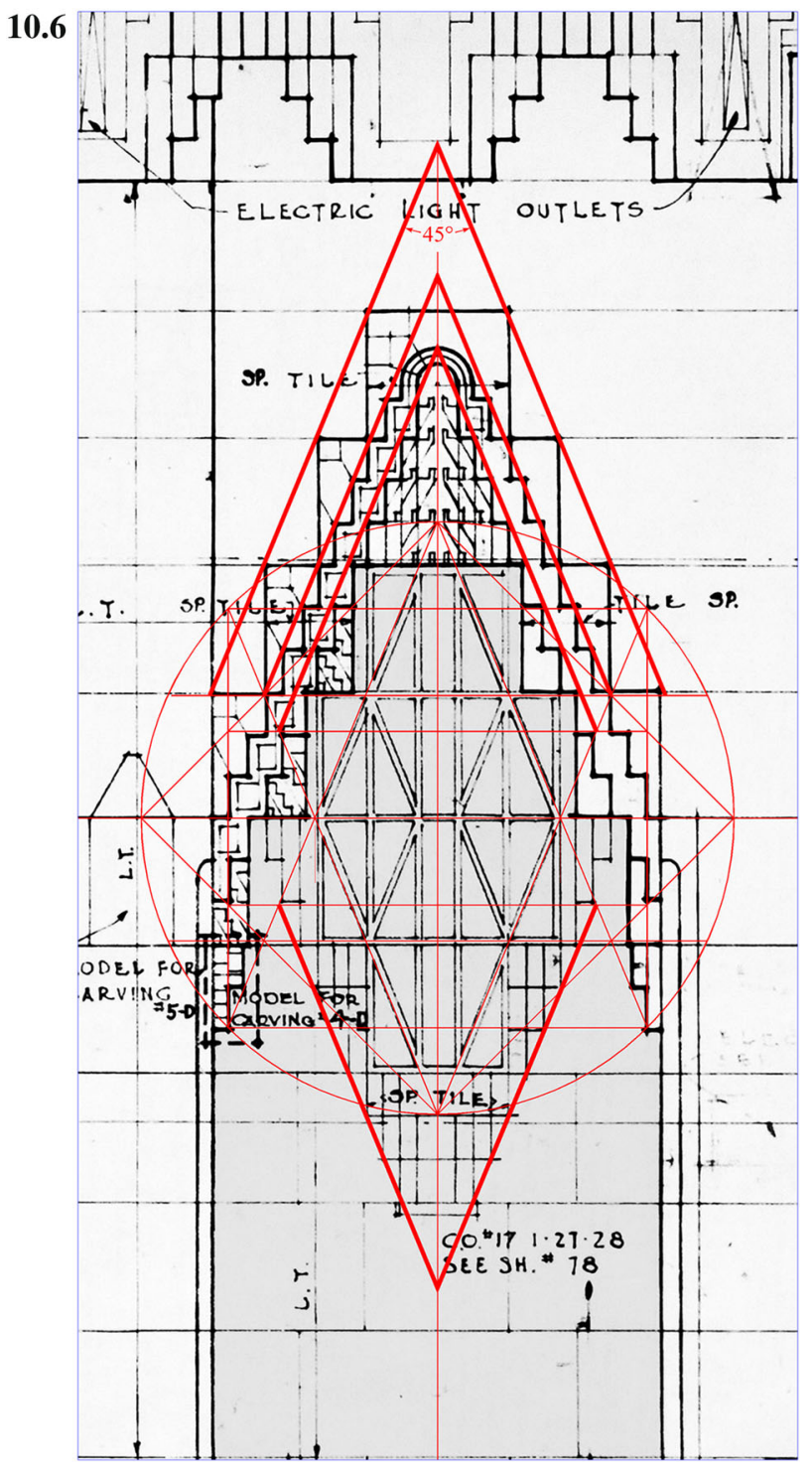

Fig. 10.1-10.7 continued

\section{Congress street entry spiral}

Hambidge calls incommensurable ratios "dynamic", because they repeat through endless spatial divisions. He calls "static" those ratios comprised of whole numbers, which do not divide in this way. He maintains that dynamic symmetry expresses "life and movement.... It produces the only perfect modulating process.... It is the 


\section{7}

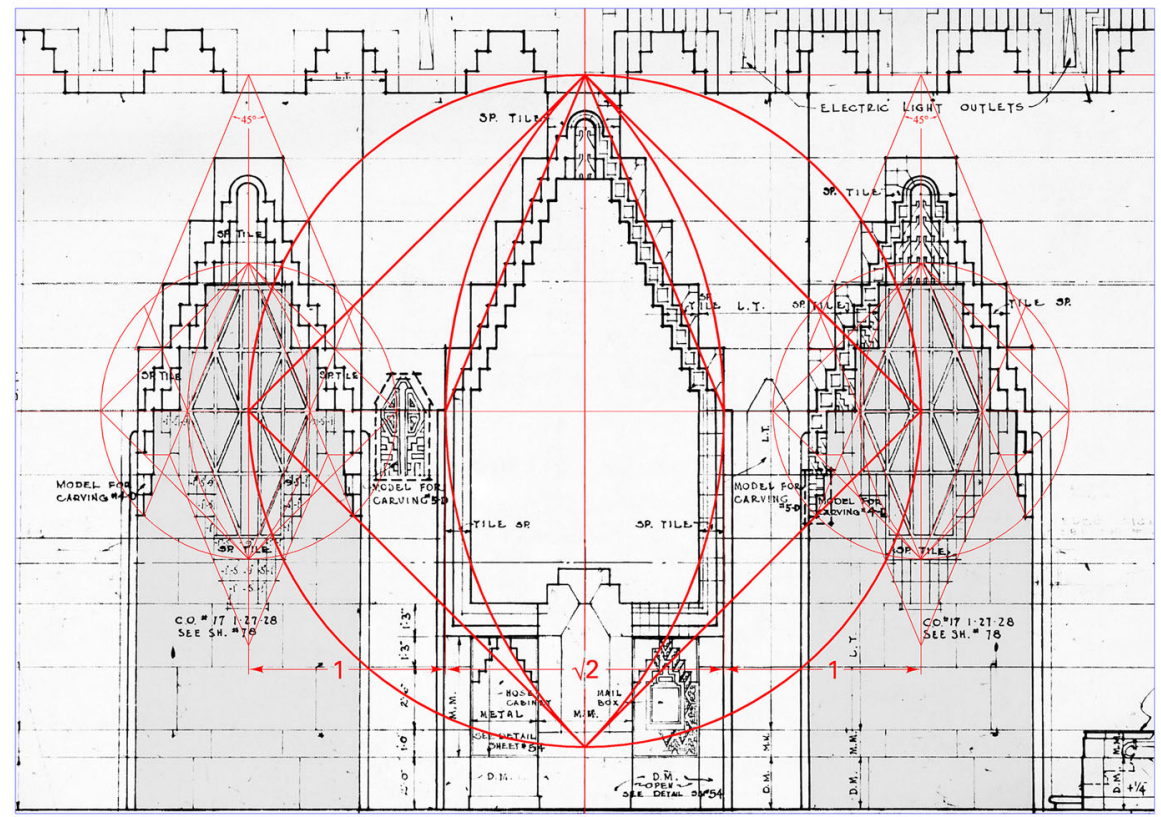

Fig. 10.1-10.7 continued

symmetry of man and plants" that governs the spiral-like growth of shells and the arrangement of leaves about a plant (Hambidge 1967: pp. xv-xvi).

The measured plans for Rowland's Guardian Building call for a spiral-like ornament on either side of the Congress Street entrance, at the base of the arch (Fig. 11). Its rectilinear scheme departs from the Guardian's more typical stepped and angled motifs. In fact, the spiral decoration was never executed, possibly due to the difficulty of carving its complex features in stone. A similar, but simpler design appears in its stead.

The original Congress Street spiral demonstrates a specific technique of dynamic symmetry. In Hambidge's system, the complementary area of a rectangle is the area that remains when the rectangle is produced within a unit square. If the rectangle exhibits properties of dynamic symmetry, its complement will also (Hambidge 1967: p. 72).

- Draw square ABCD of side 1 on the short right side of the rectangular ornament.

- Draw the square's two diagonals (Fig. 12.1).

- From point A, draw a quarter arc of radius $\mathrm{AD}$ to point $\mathrm{B}$. The arc and diagonal AC intersect at point $\mathrm{G}$.

- Through point $\mathrm{G}$, draw line EF perpendicular to line AB.

Line EF divides square $\mathrm{ABCD}$ into $\sqrt{ } 2$ rectangle $\mathrm{AEFD}$ and the rectangle's complementary area EBCF; it locates a horizontal line of ornament (Fig. 12.2). 
Fig. 11 Wirt C. Rowland.

Union Trust Guardian Building.

Congress Street window with

spiral detail, measured

elevation. Image: Smith,

Hinchman and Grylls

Associates, original drawings for

the Union Trust Building, job

number 5776, sheet number 43

"North Tower Details-Stories

Grade to 7-Congress St. Elev".

August 15, 1927
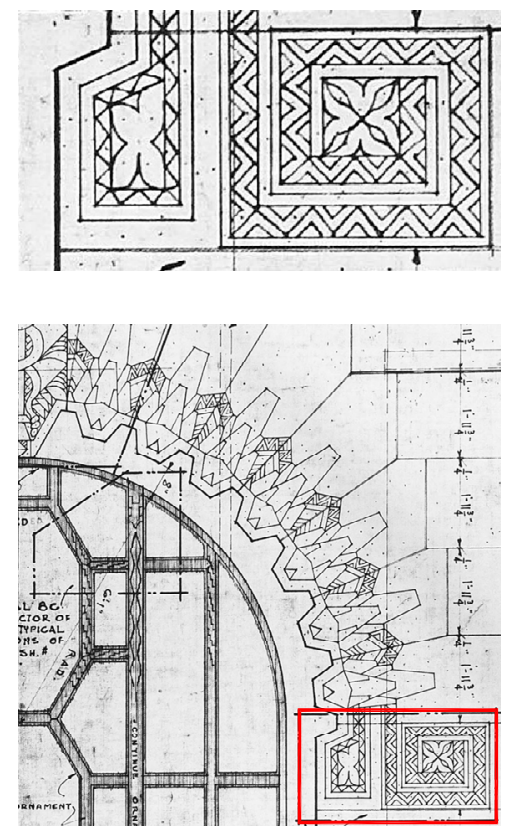

- From point D, draw a quarter arc of radius DF to point $\mathrm{H}$.

- From point H, draw line HI perpendicular to line DA.

Line $\mathrm{HI}$ divides square $\mathrm{ABCD}$ into $\sqrt{ } 2$ rectangle $\mathrm{DHIC}$ and the rectangle's complementary area HABI; it locates a vertical line of ornament (Fig. 12.3).

Lines EF and $\mathrm{HI}$ intersect at point $\mathrm{J}$.

- From point B, draw a quarter arc of radius BJ to points $\mathrm{K}$ and $\mathrm{L}$.

- From point L, draw line LM perpendicular to line AB.

- From point $\mathrm{K}$, draw line $\mathrm{KN}$ perpendicular to line BC.

Lines $\mathrm{LM}$ and $\mathrm{KN}$ intersect at point $\mathrm{O}$; they divide square $\mathrm{ABCD}$ into two squares and two $\sqrt{ } 2$ rectangles.

Side OK of square OKBL equals the short side of $\sqrt{ } 2$ rectangle OKCM.

Side MO of square MOND equals the long side of $\sqrt{ } 2$ rectangle OKCM.

Lines KN and LM locate two edges of the ornament's central square (Fig. 12.4).

- From point B, draw a quarter arc of radius BO to points $\mathrm{P}$ and $\mathrm{Q}$.

- From point P, draw line PR perpendicular to line BC.

- From point Q, draw line QS perpendicular to line AB.

Lines PR and QS intersect at point T; they divide square ABCD into two squares and two $\sqrt{ } 2$ rectangles.

Side ST of square STRD equals the short side of $\sqrt{ } 2$ rectangle STPC.

Side TP of square TPBQ equals the long side of the $\sqrt{ } 2$ rectangle STPC.

Point $\mathrm{T}$ locates the center of the ornament's center square (Fig. 12.5). 
12.1
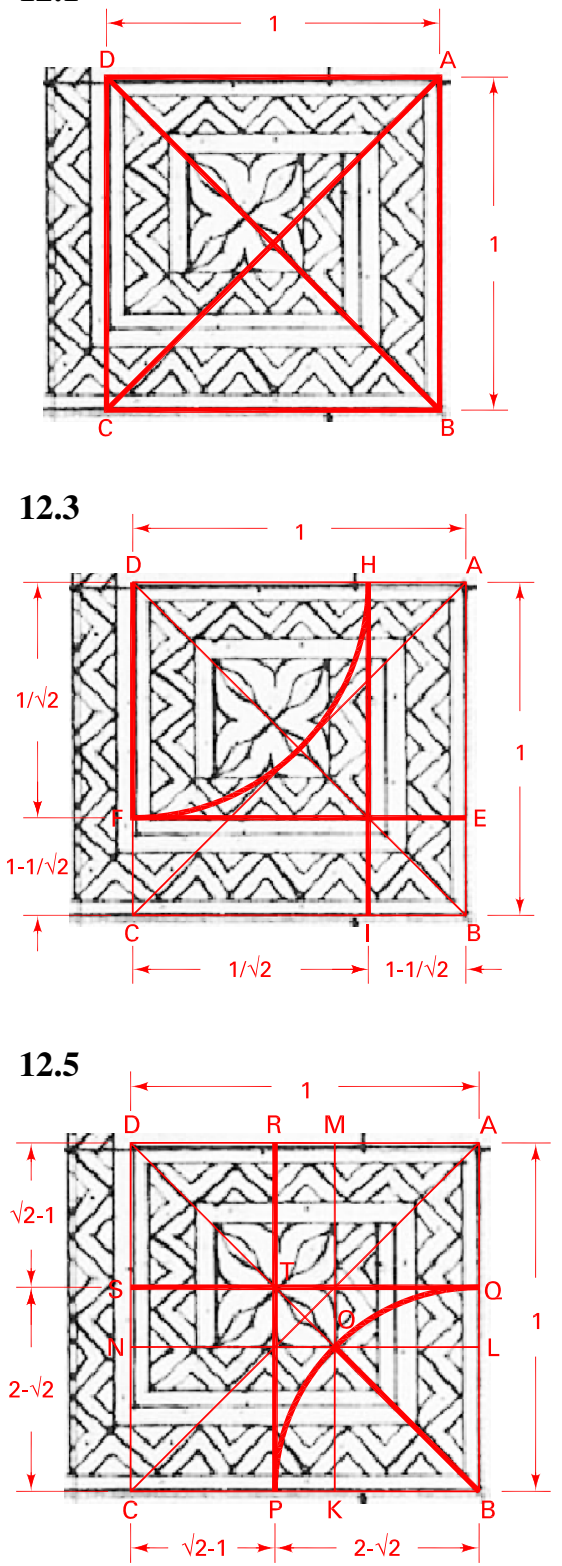

12.2

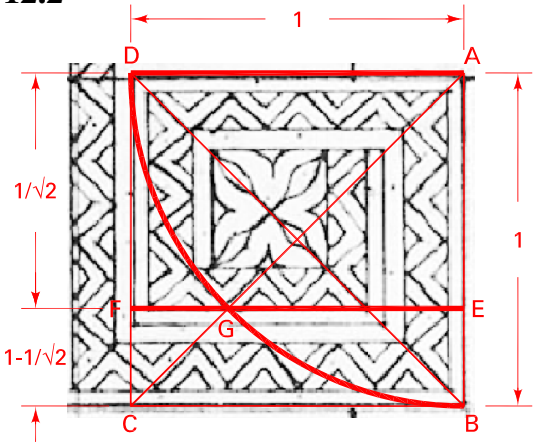

12.4

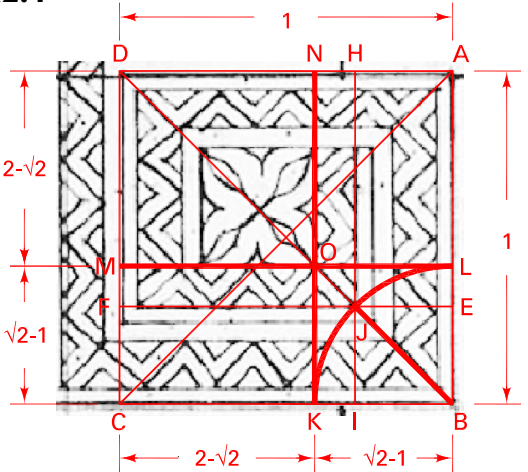

12.6

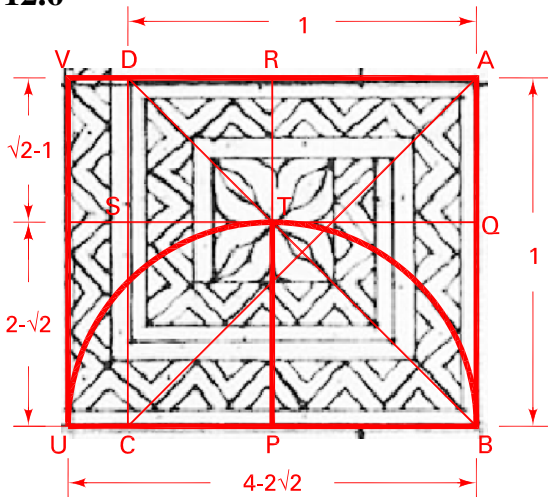

Fig. 12.1-12.6 Wirt C. Rowland. Union Trust Guardian Building. Congress Street window with spiral detail, measured elevation. Overlays by Rachel Fletcher

- From point $\mathrm{P}$, draw a semi-circle of radius PT to points B and U.

- From point U, draw line UV perpendicular to line UB.

- Connect points $\mathrm{A}, \mathrm{B}, \mathrm{U}$, and V. 
Fig. 13 Sacred cut. Image:

Rachel Fletcher
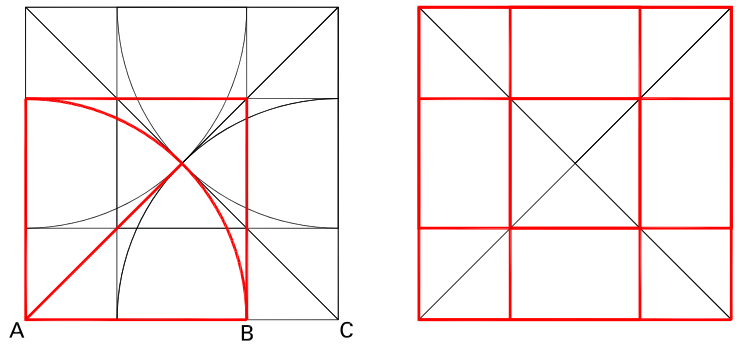

$A B: A C:: 1: \sqrt{ } 2$

Rectangle ABUV contains two squares and two $\sqrt{ } 2$ rectangles; it locates the outside extent of the ornament. Note that lines BU and UV align with lightly drawn construction lines in the measured plan (Fig. 12.6).

It is not certain that Rowland applied a proportional technique to the Congress Street spiral or, if he did, that he employed dynamic symmetry. In fact, the geometric method Tons Brunés named "sacred cut" can also produce the spiral's underlying scheme. It divides a square into $\sqrt{ } 2$ proportions by drawing arcs equal in radius to the square's half-diagonal (Fig. 13, left). The result is composed of one center square, four smaller corner squares, and four $\sqrt{ } 2$ rectangles [Brunés 1967: 100-01] (Fig. 13, right).

\section{Conclusion}

We cannot say for certain that the geometric lattices of Viollet-le-Duc and others represent the designs of medieval masons and architects, or if Hambidge's dynamic symmetry produced the classical structures of antiquity. Nor can we say with absolute certainty that these or any other geometric techniques influenced Rowland's work. It is prudent to heed Robert Bork's warning; his excellent case studies analyze extant architectural drawings of the Gothic period for evidence of geometric methods (Bork 2011). When we apply geometric overlays to a drawing or building, we can only surmise that the points we emphasize were equally meaningful to the designer. In addition, our personal bias for a particular technique colors what we see. ${ }^{11}$

Rowland's writings and sketches demonstrate that proportion ranked high among the time-honored architectural principles he sought to apply to modern-day innovations and challenges. The bold geometric patterns that adorn the Guardian's surfaces announce that geometry is in play. We cannot say definitively that Rowland employed geometric proportioning techniques. But we can reconstruct significant

\footnotetext{
11 Some source drawings provide evidence of geometric applications in the form of construction lines and compass points; these should support any theory proposed. Bork notes that hand-drawn geometric overlays can be imprecise, especially those composed of networks of lines that span long distances. The recent availability of CAD-based computer software ensures unprecedented precision (Bork 2011: p. 11). The analyses in this article were prepared in this fashion.
} 
portions of the Guardian's design with dynamic symmetry, ad quadratum, and ad triangulum constructions.

Acknowledgments We wish to thank Jeff Hausman and Paul Tonti of SmithGroupJJR, formerly Smith, Hinchman and Grylls Associates, for their generous assistance.

\section{References}

Architectural Yearbook. 1927. Dynamic Symmetry in Pattern Design and Architectural Masses. The Architectural Yearbook of the University of Michigan. Colleges of Engineering and Architecture. Ann Arbor: The Architectural Society, University of Michigan.

Board of Education. 1925. Course of Study, Art Education, Elementary Schools: Grades One to Eight. Detroit: Board of Education. http://catalog.hathitrust.org/Record/001883938. Accessed 11 May 2014.

Bork, Robert. 2011. The Geometry of Creation: Architectural Drawing and the Dynamics of Gothic Design. Farnham: Ashgate.

Breiby, John C. 1925. Design in the Drafting Room, III. Pencil Points VI 6 (June 1925): 67-72, 84.

Briggs, L.B.R. 1912. Reports of departments: the faculty of arts and sciences. Reports of the President and the Treasurer of Harvard College 1910-11. Official Register of Harvard University IX, 8 (April 2, 1912): 31-76.

Brunés, Tons. 1967. The Secrets of Ancient Geometry-and Its Use, vol. 1 (trans: Charles M. Napier). Copenhagen: Rhodos.

Cushing, Franklin Hamilton. 1886. A Study of Pueblo Pottery as Illustrative of Zuni Culture-Growth. Washington DC: Government Printing Office.

D. D. K. 1929. Color in Bank Buildings. The Christian Science Monitor (June 30, 1929): 8.

Detroit News. 1930. Scarabs hold Second Decorative Arts Show. The Detroit News Music and Art (February 9, 1930): 1.

Detroit Public Library. 1925. Architecture: A List of Books in the Detroit Public Library. Detroit: Detroit Public Library

Hambidge, Jay. 1919. Symmetry and Proportion in Greek Art. The American Architect CXVI 2290 (November 12, 1919): 597-605.

Hambidge, Jay. 1920. Dynamic Symmetry: The Greek Vase. New Haven: Yale University Press.

Hambidge, Jay. 1921a. Dynamic symmetry and modern architecture. Architecture XLIV 5 (November 1921): 343-45.

Hambidge, Jay. 1921b. Dynamic Symmetry: The Rediscovery of the Basic Principles of Greek Art. Scientific American Monthly IV 1 (July 1921): 23-28.

Hambidge, Jay. 1967. The Elements of Dynamic Symmetry. Reprinted (1926). New York: Dover.

Kimball, Fiske, and George H. Edgell. 1918. A History of Architecture. New York: Harper and Brothers.

Nordenskiöld, G. 1893. The Cliff Dwellers of Mesa Verde: Their Pottery and Implements. Stockholm: Royal Printing Office.

Peet, Stephen Denison. 1899. The Cliff Dwellers and Pueblos. Chicago: Office of the American Antiquarian.

Richards, W. C. 1929. Trust Building Opens Tuesday. Detroit Free Press (March 31, 1929): 1, 3.

Rollins, J. Frank. 1921. University of Michigan News. Wirt. C. Rowland, Chairman. Michigan Architect and Engineer III 5 (May 1921): 68.

Rowland, Wirt C. 1910a. Letter to Wallace Sabine, Harvard University (August 27, 1910). Harvard University, Graduate School of Design records (UAV 322.282).

Rowland, Wirt C. 1910b. Special Student Registration: Architecture (September 28, 1910). Harvard University, Graduate School of Design records (UAV 322.282).

Rowland, Wirt C. 1929. New Note in Architecture Struck. The Detroit News. Special roto section (March 31, 1929): 3 .

Rowland, Wirt C. 1931. Real Progress. Architectural Progress V 8 (August 1931): 15-16, 23.

Rowland, Wirt C. 1932. Symposium on modernism. Weekly Bulletin of the Michigan Society of Architects VI 24 (June 14, 1932): 1, 4-8.

Rowland, Wirt C. 1939. Sunday's Child. Weekly Bulletin of the Michigan Society of Architects XIII 3 (January 17, 1939): 1, 4-8. 
Rowland, Wirt C. 1940. Human-All too Human-Chapter III. Weekly Bulletin of the Michigan Society of Architects XIV 17 (April 23, 1940): 1, 4.

Special Art Course. 1921. The Detroit Educational Bulletin V 2 (October 1921): 14.

University of Michigan. 1926. General Announcement 1926-1927. Colleges of Engineering and Architecture. Ann Arbor: University of Michigan. http://hdl.handle.net/2027/mdp.39015023952800. Accessed 11 May 2014.

University of Michigan. 1927. Catalogue 1926-1927. General Register. Ann Arbor: University of Michigan. http://hdl.handle.net/2027/mdp.39015023277380. Accessed 11 May 2014.

Viollet-le-Duc, Eugène Emmanuel. 1875. Discourses on Architecture (trans: Henry Van Brunt). Boston: James R. Osgood and Company. http://www.archive.org/details/discoursesonarc00violgoog. Accessed 11 May 2014.

Villard de Honnecourt. 2006. The Medieval Sketchbook of Villard De Honnecourt. New York: Dover.

WSJ. 1929. New bank home in Detroit ready, magnificent 40-story building. Wall Street Journal (April 1, 1929): 4.

Michael G. Smith is an independent researcher living in Bloomfield Hills, Michigan. He was born and raised in Cincinnati, Ohio. With a degree in philosophy from Oakland University, his early career was in the printing and publishing industry as a graphic artist. He left the field to become an executive recruiter. From an early age, Smith had an interest in fine art and photography, receiving his first camera at age six as a gift from his grandfather, a commercial artist. Smith's photographs have appeared in national publications and on websites, including Fodor's, Travelocity, National Geographic, NBC News, and U.S. News. Smith researches and writes on urban history and architecture. His book on the life and work of Wirt Rowland is due in 2016.

Rachel Fletcher author of Infinite Measure: Learning to Design in Geometric Harmony with Art, Architecture, and Nature, is a geometer and teacher of geometry and proportion to design practitioners. With degrees from Hofstra University, SUNY Albany and Humboldt State University, she was the creator/curator of the museum exhibits "Infinite Measure", "Design by Nature", and "Harmony by Design: The Golden Mean", and author of the exhibit catalogs. She has been a faculty member of the New York School of Interior Design since 1996 and a contributing editor to the Nexus Network Journal since 2005. Fletcher is founding director of the Housatonic River Walk in Great Barrington, Massachusetts, and co-director of the Upper Housatonic Valley African American Heritage Trail. 